\title{
Composition and Stoichiometry Effects of Biogas as Fuel in Spark Ignition Engine
}

\author{
C. Mokrane ${ }^{1 *}$, B. Adouane ${ }^{2}$ and A. Benzaoui ${ }^{1}$ \\ ${ }^{1}$ USTHB University, Faculty of Physics, Fluid Mechanics and Energy, BP 32 El Alia \\ 16111, Bab Ezzouar, 16111. Algiers, Algeria \\ *Email: ch.mokrane@gmail.com \\ Phone: +213663716687; Fax: + (213) 33819895 \\ ${ }^{2}$ University of Batna 1- Faculty of Material Sciences, Laboratory (APEL), Route de \\ Biskra, 05000. Batna, Algeria
}

\begin{abstract}
The most important advantage of biogas is that one can retrofit easily the conventional combustion engines to be used for the new fuel but remain the problem of pollutant emission. In this paper, the effect of the biogas composition on the emissions of $\mathrm{CO}$ and NOx in an SI engine is investigated numerically. Three compositions were studied $\left(\mathrm{CH}_{4}: 40 \%, \mathrm{CO}_{2}: 60 \%\right),\left(\mathrm{CH}_{4}: 50 \%, \mathrm{CO}_{2}: 50 \%\right),\left(\mathrm{CH}_{4}: 60 \%, \mathrm{CO}_{2}: 40 \%\right)$, at equivalence ratio $(\phi)$ from lean to rich. The non-adiabatic partially premixed combustion model with probability density function (PDF) method and Zimont model of the turbulent flame speed are used. It was found that increasing $\mathrm{CO}_{2}$ in the biogas lowers $\mathrm{NOx}$ emissions significantly, whereas, $\mathrm{CO}$ was found to be very low, and appears only at high $\mathrm{CH}_{4}$ concentration. A biogas with $\left(\mathrm{CH}_{4}: 60 \%, \mathrm{CO}_{2}: 40 \%\right)$, burning at about $(\phi=0.9)$, i.e. slightly lean mixture, and advanced spark timing (between 10 to $20^{\circ}$.) seems to be a very a realistic combination in terms of biogas composition, stoichiometry and spark timing. It is recommended that, to accomplish some upgrading, in case of biogases with low $\mathrm{CH}_{4}$ percentage, to get it up to $60 \%$.
\end{abstract}

Keywords: Biogas composition; partially premixed combustion; SI engine; emissions; numerical simulation.

\section{NOMENCLATURE}

$\begin{array}{ll}\text { BG60 } & \begin{array}{l}\text { biogas with } 60 \% \text { of } \mathrm{CH}_{4} \\ \text { BTDC }\end{array} \\ \text { cefore top dead center } \\ \text { progress variable of reaction } \\ \text { CA } & \begin{array}{l}\text { crankshaft angle } \\ \text { computational fluid dynamic }\end{array} \\ \text { CFD } & \text { carbon monoxide } \\ \mathrm{CO} & \text { carbon dioxide } \\ \mathrm{CO}_{2} & \text { hydrogen sulfide } \\ \mathrm{H}_{2} \mathrm{~S} & \text { nitrous oxides } \\ \mathrm{NOx} & \text { probability density function } \\ \text { PDF } & \text { revolutions per minute }\left(\mathrm{r} \cdot \mathrm{min}^{-1}\right) \\ \text { rpm } & \text { spark ignition } \\ \text { SI } & \text { solid waste } \\ \text { SW } & \text { total hydrocarbons } \\ \text { THC } & \text { user-defined function }\end{array}$




\section{INTRODUCTION}

Among the problems facing humanity, the most important One is the problem of the search for new, alternative energy sources. This is connected with the dwindling resources of fossil fuels, particularly petroleum, as well as growing concern for the natural environment and the fight against global warming [1]. The valorization of solid waste (SW) becomes a vital environmental necessity. One of the most important ways to promote these $\mathrm{SW}$ is to recover landfill gas and use it for energy purposes. Biogas is a biodegradable and renewable source of energy formed by the anaerobic digestion of organic material. Biogas is extracted from different sources such as households and gastronomy wasters, wastes of fodder and food industry, vegetable and animal wastes, and waste from productive livestock husbandry, among others [2]. It consists of a variable proportion of $\mathrm{CH}_{4}$ (methane); $\mathrm{CO}_{2}$ (carbon dioxide) and trace amounts of $\mathrm{H}_{2} \mathrm{~S}, \mathrm{~N}, \mathrm{CO}, \mathrm{O}$, etc. The content of $\mathrm{CH}_{4}$ and $\mathrm{CO}_{2}$ is a function of the digested material and processing conditions such as temperature, the ratio of $\mathrm{C} / \mathrm{N}$, etc.

The quality of biogas as a fuel for SI engine is related to some parameters. The calorific value of the biogas is a vital parameter for the performance of an engine. The calorific value of the biogas is a function of the $\mathrm{CH}_{4}$ percentage, the temperature, and the absolute pressure, all of which differ from case to case. The large quantity of $\mathrm{CO}_{2}$ present in biogas lowers its calorific value, flame velocity, and flammability range compared with natural gas. After being cleaned of carbon dioxide, the biogas becomes a homogeneous fuel containing up to $80 \%$ of methane with the calorific capacity of over $25 \mathrm{MJ} / \mathrm{m} 3$. The self-ignition temperature of biogas is high and hence it resists knocking which is desirable in SI engines. Thus, biogas has a high anti-knock index and hence biogas engine can use high compression ratios, which can lead to improvements in thermal efficiency [3].

The use of biogas in the engines (when compared to fossil fuels) avoids any additional greenhouse gas emissions. Due to organic nature of the components of biogas, burning it in a gas engine for power generation emits the same amount of $\mathrm{CO}_{2}$ into the atmosphere as was originally absorbed during the process of photosynthesis in the natural $\mathrm{CO}_{2}$ [4]. The useful energetic part of the biogas is methane. The other components have an energy content as well, but they are not participating in a combustion process. Instead, they absorb energy from the $\mathrm{CH}_{4}$ combustion while leaving the process usually at a high temperature (exhaust). Some studies showed that carbon dioxide present in biogas can have chemical effects when it participates in chemical reactions due to thermal dissociation and thermal effects when it acts as a diluent [5]. When the amount of $\mathrm{CO}_{2}$ in biogas is important it reduces heating value, flammability range, flame stability and laminar burning velocity. $\mathrm{CO}_{2}$ in this study is considered inert and absorbing energy from $\mathrm{CH}_{4}$ combustion.

Biogas, once recovered, it is analyzed then filtered to eliminate or decrease the harmful elements. Treated biogas, will be ready to use as fuel. The internal combustion engine presents a great candidate for biogas. Biogas reducing $\mathrm{CO}_{2}$ and $\mathrm{NO}_{\mathrm{X}}$ emission, more complete and efficient burning with less unburned hydrocarbons present in the exhaust compare to fossils fuel [6]. Natural gas and biogas have been found to possess good resistance to knocking. Their octane numbers are higher than that of petrol: for natural gas at 120 [7] and biogas with a composition of $65 \% \mathrm{CH}_{4}$ and $35 \% \mathrm{CO}_{2}$ at 136 [8]. The engines can, therefore, be operated at a higher compression ratio for better 
efficiency. The choice of compression ratio for biogas is thus based to some extent on the composition of biogas.

In all previous studies, it is not simple to obtain common operating conditions for engines fuelled by biogas because there is a significant difference in the composition of the fuel, therefore, the effects of the biogas composition on the emissions of the engine must be investigated. The optimization of the combustion of biogas in an internal combustion engine and the minimization of different emissions has been the subject of several studies. Porpatham [9] examined the effect of the concentration of methane in biogas used as a fuel in an SI engine. They observed that the increase in methane concentration in biogas enhances the performance significantly and reduces the emissions of the hydrocarbons. The true utility of the $\mathrm{CO}_{2}$ removal from biogas is obtained when the engine is operating with a lean mixture of air/fuel in the range of the equivalence ratio between (0.8 and 0.95). Moreover, the elimination of $\mathrm{CO}_{2}$ from biogas results in higher methane and oxygen concentrations in the charge and thus leads to a faster combustion and higher power outputs at a given equivalence ratio. Huang [10] presented results of tests with a variable compression ratio Ricardo E6 single-cylinder spark-ignition engine operating on simulated biogas formed from different mixtures of domestic natural gas and carbon dioxide. $\mathrm{CO}_{2}$ fraction changed from $0 \%$ to about $40 \%$ by volume to cover the range typically encountered in sources of biogas in practice. The tests covered a range of air/fuel ratios from rich to the lean operating limit at four speeds and a number of compression ratios. Experimental results indicate that the main influence of carbon dioxide in the biogas fuel on engine operation was to lower the NOx emissions and enable the compression ratio to be increased. The total hydrocarbon emissions were also increased with the presence of $\mathrm{CO}_{2}$ in the fuel. They found that when running with lean fuel mixtures, the $\mathrm{CO}$ emissions were low and did not change with the $\mathrm{CO}_{2}$ fraction in the biogas. At rich mixtures and $\mathrm{CO}_{2}$ fraction above $30 \%, \mathrm{CO}$ emissions went up rapidly, this is mainly due to incomplete combustion. The $\mathrm{CO}$ emissions correlated with the relative air-to-fuel ratio and were almost unaffected by compression ratio and engine speed. According to Jung et al. [11], the combustion behaviors were improved as the $\mathrm{CH}_{4}$ content in the biogas increased. The lean operation limit was extended up to a relative air/fuel ratio of 1.5 with various biogas compositions and up to a relative air/fuel ratio of 1.7 for $\mathrm{CH}_{4}: \mathrm{CO}_{2}$ volume ratios of $65: 35 \%$ and $70: 30 \%$ without knocking. The NOx emissions were reduced by more than $90 \%$ via a reduction in the combustion temperature, which was achieved as a result of the lean combustion.

The study of Lee [12], showed that the presence of $\mathrm{CO}_{2}$ in the fuel decreases the performance of the engine and produces more pollutants in the emissions compared to the pure $\mathrm{CH}_{4}$. Engine efficiency was decreased by mixing with $\mathrm{CO}_{2}$ at same load conditions. As $\mathrm{CO}_{2}$ fraction in a fuel increased, the equivalence ratio increased, which means more fuel was needed to generate the same power output. NOx slightly decreased whereas $\mathrm{CO}$ and THC (total hydrocarbons) increased with a $\mathrm{CO}_{2}$ fraction. NOx slightly decreased whereas $\mathrm{CO}$ and THC increased with a $\mathrm{CO}_{2}$ fraction. Bedoya et al. [13] made a numerical analysis of the effect of the composition of biogas on the parameters of its combustion as well as the emissions in the HCCI engine (Homogeneous Charge Compression Ignition ); they concluded that NOx emissions are not highly affected by biogas composition, while $\mathrm{CO}$ and unburned hydrocarbons (HC) emissions tend to increase with higher contents of $\mathrm{CO}_{2}$. Abader [14] studied a biogas-fuelled SI engine simulated by fuel mixtures consisting of natural gas and $\mathrm{CO}_{2}$; the effects that fuel composition has on emissions and catalyst performance were investigated. Engine-out THC and NOx increased and decreased, respectively, with increasing $\mathrm{CO}_{2}$ in the fuel 
mixture. Doubling the catalyst residence time doubled the conversion of THC and CO emissions. The effectiveness of the catalyst at converting THC emissions was found to be dependent on the relative proportions of engine-out THC, NOx and $\mathrm{CO}$ missions. Arroyo [15] found that $\mathrm{CO}$ and $\mathrm{CO}_{2}$ content in the composition of synthetic gases contributed to increasing the exhaust concentrations of these pollutants compared with the other fuels, while THC decreased because of the small fraction of methane, which remained unburned. Although $\mathrm{NOx}$ emissions were mitigated by diluents, like $\mathrm{CO}_{2}$ and air excess, high hydrogen fraction in the composition of syngas involved elevated NOx emissions due to the increase in flame temperature that hydrogen produces. Pablo [16] conducted an investigation used a diesel engine with a maximum output power $8.5 \mathrm{~kW}$, which was converted to spark ignition mode to use it with gaseous fuels. Three fuels were used: simulated biogas, biogas enriched with 25 and $50 \%$ methane by volume. It was found that the presence of carbon dioxide allows operating engines at high compression ratios with normal combustion conditions. Emissions of nitrogen oxides, carbon monoxide, and unburnt methane decreased when the biogas was enriched with $50 \%$ methane. More research is done which was focused on different biogas composition effects on engine application [17], [18], [19], [20], [21].

Despite the efforts of above survey that have been devoted to investigating the biogas combustion and emissions, a comprehensive understanding of these emissions over a wide range of operating conditions focusing on carbon dioxide concentration still needs a deep investigation. The main goal of this study is to explore numerically the effect of biogas composition, in terms of $\mathrm{CO}_{2}$ and $\mathrm{CH}_{4}$, on emissions of its combustion, especially NOx and CO in spark ignition engine, under given operating conditions. The paper is organized into four sections. After a brief explanation of the theoretical approach, a general description of the simulation details is briefly explained. The numerical simulation results and discussion respective are then presented. Validation and the findings of the present study are summarized at the end.

\section{METHOD AND MATERIALS}

\section{Biogas Combustion in SI Engine}

The most important process on internal combustion engines is combustion process, and one of the important parts of engine modeling is combustion modeling [22]. Until now, there were some studies on the performance and the emissions of biogas combustion in SI engine [13], [23]; however, there is not enough information available on the process of combustion itself.

The process of combustion in the Spark Ignition engines can be divided into three large areas [24]: (1) ignition and flame development, (2) flame propagation, and (3) flame termination. Flame development is generally considered in the consumption of the first 5 $\%$ of the air-fuel mixture (some sources use the first $10 \%$ ). During the flame development period, ignition occurs, and the combustion process starts, but very little pressure rise is noticeable and little or no useful work is produced. Almost all useful work produced in an engine cycle is the result of the flame propagation period of the combustion process. This is the period when the bulk of the fuel and air mass is burned (i.e., 80-90\%, depending on how defined). During this time, the pressure in the cylinder is greatly increased, and this provides the force to produce work in the expansion stroke. The final $5 \%$ (some sources use $10 \%$ ) of the air-fuel mass, which burns, is classified as flame termination. During this time, pressure quickly decreases, and combustion stops. In SI 
engine, combustion ideally consists of an exothermic subsonic flame progressing through a premixed homogeneous air-fuel mixture. The spread of the flame front is greatly increased by induced turbulence, swirl, and squish within the cylinder. The right combination of fuel and operating characteristics is such that knock is avoided or almost avoided. The process of combustion in SI engines depends strongly on the field speed and the level of turbulence in the combustion chamber at the time of spark ignition; it depends also on the pressure, temperature, and the mixing gas in the cylinder [25].

\section{Modeling Biogas Combustion in SI Engine}

The computational fluid dynamics (CFD) is a very useful tool used to investigate numerically the combustion process evolution. For this reason, this tool was selected in this work to characterize the process of combustion. The software ANSYS-FLUENT, which is based on the method of finite volumes, is used to carry out the simulation. For SI engines and some engines using the combustion of natural gas, the fuel, and the air are mixed before entering the combustion chamber. At the time of the spark, the mixture is supposed to be homogeneous and the process is known as "premixed combustion". Since the premixed combustion model does not consider any species, this would result in a bad maximum temperature and pressure. The partially premixed combustion model of ANSYS- FLUENT considers the composition at equilibrium and can be employed for the premixed combustion for which one can have a better prediction of the maximum temperature and pressure. The simulation starts with the closing of the valve of admission (intake closed valve: ICV) and finishes with the opening of the exhaust valve (exhaust open valve: EOV). Thus, there is no implied valve. An approach of purely "layering" is employed on a 2D axisymmetric geometry. Symmetry is employed in the geometry to reduce the size of the field to half, thus reducing the number of cells and improving the speed of calculations [26] as in Figure 1 (a) and (b). The specifications of the simulated engine are presented in Table 1.

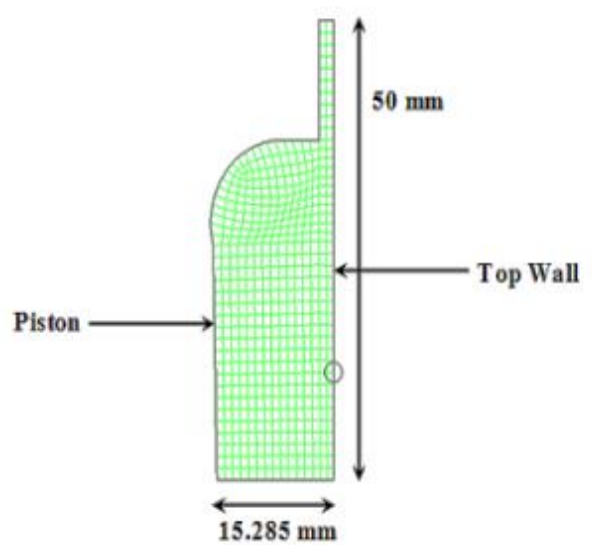

(a)

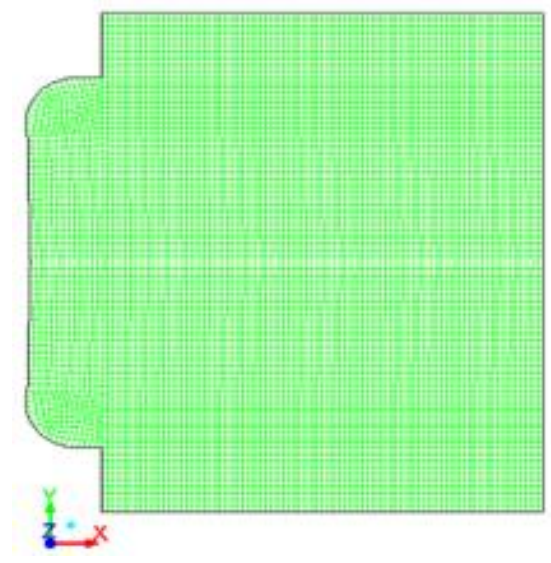

(b)

Figure 1. (a) Computational domain and; (b) the cylinder and combustion chamber [26]. 
Table 1. Simulated engine specifications

\begin{tabular}{lc}
\hline Parameter & Value \\
\hline Number of cylinder & 1 \\
Crank shaft speed (rpm) & 1500 \\
Starting crank angle $\left(^{\circ}\right)$ & 360 \\
Crank period $\left(^{\circ}\right)$ & 720 \\
Crank angle step size $\left(^{\circ}\right)$ & 0.25 \\
Piston stroke $(\mathrm{mm})$ & 80 \\
Connecting rod length $(\mathrm{mm})$ & 140 \\
Compression ratio & $6.23: 1$ \\
\hline
\end{tabular}

\section{Combustion Model}

Partially premixed combustion systems are premixed flames with non-uniform fueloxidizer mixtures (equivalence ratios). Such flames include premixed jets discharging into a quiescent atmosphere, lean premixed combustors with diffusion pilot flames and/or cooling air jets, and imperfectly premixed inlets [27]. In partially premixed combustion, we find the premixed and non-premixed conditions. We employ the method of probability density function (PDF) to detect the mixture fraction and to model chemistry in the system (used for cases of premixed and non-premixed combustion). The Zimont model of the turbulent flame speed is used to enclose the turbulent quantities, typically used for cases of premixed combustion [28]. The non-premixed model of combustion solves transport equations for conserved scalar and mixture fractions. The actual chemical quantities of species are derived from the distribution given by mixture fraction deducted from PDF tables' (probability density function). The aim of using PDF method is to track the mixture fraction and modeling the chemistry in the system. For the components of the premixed combustion, which were solved at the time of execution of the simulation, the Zimont model of the turbulent flame speed includes the speed of laminar flame (which determines the chemistry of the system) and the evolution of the flame front due to turbulence [29], [30]. We adapt the assumption that turbulence scale in the flame is smaller than the thickness of flame, a number of Karlovitz Ka $>$ (If $\mathrm{Ka} \ll<1$ the chemical reactions occur much faster than all turbulent scales). The combination of these two models is the object of partially premixed combustion. The progress variable of reaction " $c$ " is employed to locate the site of the flame, called the flame front. Before (on the left of) the flame front for $c=0$, the mixture is not burned, and the mass fractions and other variables are calculated by using the mixture fractions deducted by the PDF.

Inside the flame, a combination of the two models is employed. In the burned sector (on the right of the flame for $c=1$ ), the equilibrium mixture fraction is calculated. While the flame is introduced into the chamber, the progress variable "c" is placed at the value " 1 ", and this propagates in all the fuel according to the flame speed. In Fluent Zimont model, the laminar flame speed by default is a constant. Laminar flame speed is a strong function of temperature and equivalence ratio. Therefore, we use a UDF to modify the laminar flame speed to be a more realistic (recomputing the flame speed based on the pressure, the temperature, and the mixture fraction inside the cylinder) [27]. Another UDF provides a tool to initialize the flow field with user-specified swirl ratio (because combustion and power stroke is of interest for this internal combustion flow, the initial condition normally contains swirl flow). The model of turbulence used is the k- $\varepsilon$ 
model with two equations. Table 2 summarizes the combustion model. Concerning governing transport equations, we can find details in [27].

Table 2. Combustion model.

\begin{tabular}{ll}
\hline Model: & Partially premixed combustion \\
\hline Premixed model & C-equation \\
Turbulent flame speed model & Zimont \\
State relation & Chemical equilibrium \\
Energy treatment & Non-adiabatic \\
Equilibrium operating pressure $(\mathrm{Pa})$ & 3000000 \\
PDF options & Inlet diffusion and compressibility \\
& effects \\
Temperature $\left({ }^{\circ} \mathrm{K}\right)$ & 300 \\
\hline
\end{tabular}

\section{NOx Modelling and CO Formation}

Concerning NOx reduction, Chavero [31], conducted a numerical analysis of NOx reduction from biogas combustion in order to assess the feasibility of the alternate method of NOx destruction using chemical equilibrium, kinetics, and computerized fluid dynamic simulations. The author found that to maximize NOx reduction in a Compression Ignition Engine, The Equivalence ration should be increased to near 1.0. instead of, Increase the reactant temperature to an average temperature of $700^{\circ} \mathrm{K}$, this can be done by a high compression ratio and increase the concentration in the sweep gas to a ratio of 5 to 10 percent. Under those parameters, the pressure was found to have no significant effect.

In this study, for NOx modeling, we have used the ANSYS FLUENT thermal and prompt model. The formation of thermal NOx is determined by a set of highly temperature-dependent chemical reactions known as the extended Zeldovich mechanism [32]. For prompt NOx formation [33], it is known that during combustion of hydrocarbon fuels, the NOx formation rate can exceed that produced from the direct oxidation of nitrogen molecules (that is, thermal NOx). There is good evidence that prompt NOx can be formed in a significant quantity in some combustion environments, such as in lowtemperature, fuel-rich conditions and where residence times are short [27].

Carbon monoxide (CO) emissions from internal combustion engines are controlled primarily by the fuel/air equivalence ratio. For fuel-rich mixtures, $\mathrm{CO}$ concentrations in the exhaust increase steadily with increasing equivalence ratio, as the number of excess fuel increases. For fuel-lean mixtures, $\mathrm{CO}$ concentrations in the exhaust vary slightly with equivalence ratio and are of the order $10^{-3}$ mole fraction [34]. We can use for simulation a mechanism with two-steps and three reactions [26], which allows the calculation of the amount of $\mathrm{CO}$ that is generated during the combustion of methane in the SI engine model. The considered reactions are:

$$
\begin{aligned}
& \mathrm{CH}_{4}+1.5 \mathrm{O}_{2} \rightarrow \mathrm{CO}+2 \mathrm{H}_{2} \mathrm{O} \\
& \mathrm{CO}+\frac{1}{2 \mathrm{O}_{2}} \rightarrow \mathrm{CO}_{2} \\
& \mathrm{CO}_{2} \rightarrow \mathrm{CO}+\frac{1}{2 \mathrm{O}_{2}}
\end{aligned}
$$


Reaction (1) describes the oxidation of methane to form CO and water, reaction (2) shows the formation of $\mathrm{CO}_{2}$ while the reaction (3) considers the dissociation reaction of the latter species.

\section{Studied Cases}

In this study, we varied the composition of biogas $\left(\mathrm{CH}_{4}+\mathrm{CO}_{2}\right)$ with the variation of the equivalence ratio $(\phi)$. The calculations were done for three various biogases according to the percentage of $\mathrm{CH}_{4}\left(\mathrm{BG} 40: 40 \% \mathrm{CH}_{4}\right.$; BG50: $50 \% \mathrm{CH}_{4}$ and BG60: $\left.60 \% \mathrm{CH}_{4}\right)$ and for each case, the equivalence ratio $\phi$ range from lean to rich operating limit (from 0.6 to 1.4) at a constant speed.

\section{Boundary Conditions}

The type of boundary conditions "axis" must be used in the center of the axisymmetric geometry. Since the geometry is symmetric, the software takes into account this fact for the axis. Therefore, there is no need to define any boundary condition of the axis. To determine the suitable physical value of a particular variable on a point of the axis, ANSYS FLUENT uses the value of the cell in the adjacent cell. The values of $\mathrm{CH}_{4}, \mathrm{CO}_{2}$, and the air are injected with a certain value of the equivalence ratio $(\phi)$, representing fuel premixed at a temperature of $300{ }^{\circ} \mathrm{K}$. In addition, the oxidant (air) will be injected like co-flow outside the flow of fuel, at $300{ }^{\circ} \mathrm{K}$. The global chemical reaction of biogas developed based on combustion theory is:

$$
\begin{aligned}
& (1-\alpha)\left[\mathrm{CH}_{4}+\left(3-\frac{1}{\emptyset}\right)\left(\mathrm{O}_{2}+3.76 \mathrm{~N}_{2}\right)\right]+\alpha \mathrm{CO}_{2} \rightarrow \mathrm{CO}_{2}+2(1-\alpha) \mathrm{H}_{2} \mathrm{O}+7.52 \\
& (1-\alpha) \mathrm{N}_{2}+\left(\frac{1}{\varnothing}-1\right)(1-\alpha)\left(\mathrm{O}_{2}+3.76 \mathrm{~N}_{2}\right)
\end{aligned}
$$

Where, $\alpha=$ mole fraction of $\mathrm{CO}_{2} ; \phi=$ equivalence ratio.

\section{RESULTS AND DISCUSSION}

\section{CO Emissions}

The variation in the percentage of biogas composition affects combustion characteristics due to differences in their properties. For example, $\mathrm{CO}$ and methane in blend decrease the speed of the flame and $\mathrm{CO}_{2}$ acts as diluents, decreasing the speed and the temperature of the flame [35]. In this study, $\mathrm{CO}$ emission could be low for lean mixtures and not sensitive to the $\mathrm{CO}_{2}$ fraction of biogas.

From Figure 3 (a), it is clear that when increasing $\mathrm{CH}_{4}$ concentration in the biogas; this decreases $\mathrm{CO}$ emission significantly in the rich zone, which is in line with the results obtained by Porpatham et al. [9]. In the rich zone, the level of $\mathrm{CO}$ increases rapidly for each biogas. This is due to the lack of oxygen - Figure 7 (a) - and more quantities of $\mathrm{CH}_{4}$ that have not enough time to be burned out. Whereas in the lean zone, $\mathrm{CO}$ falls off rapidly to zero. This effect is due to increasing the temperature by increasing the concentration of $\mathrm{CH}_{4}$, resulting in a better out of $\mathrm{CO}$.

In Figure 3 (b) the variation of $\mathrm{CO}$ emissions with the $\mathrm{CO}_{2}$ fraction in biogas shows clearly that when operating on lean and stoichiometric mixtures, the $\mathrm{CO}$ emissions 
were low and seemed to change little with the variation of the $\mathrm{CO}_{2}$ fraction in the biogas mixture [9]. Under rich mixture conditions, the carbon monoxide increased markedly when the fraction of carbon dioxide was decreased below $40 \%$. This resulted from the low burning rate and lower oxygen availability inside the engine cylinder [36].

Figure 4 shows that the major part of the $\mathrm{CO}$ concentration is located in the ignition zone on the axis of the cylinder and inside the basin of the piston. It is the result of a incomplete combustion because of the process of oxidation of $\mathrm{CO}$ to $\mathrm{CO}_{2}$ in this zone, which is a depression zone, resulting in a flow pushed up to the walls.

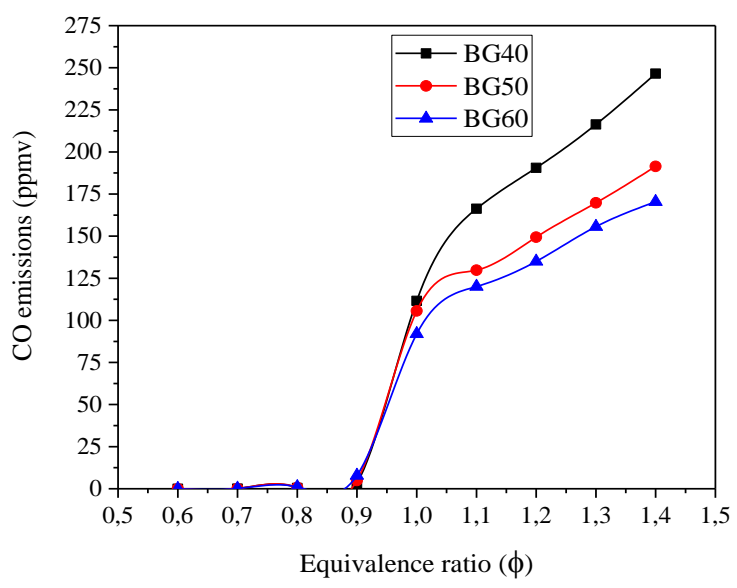

(a)

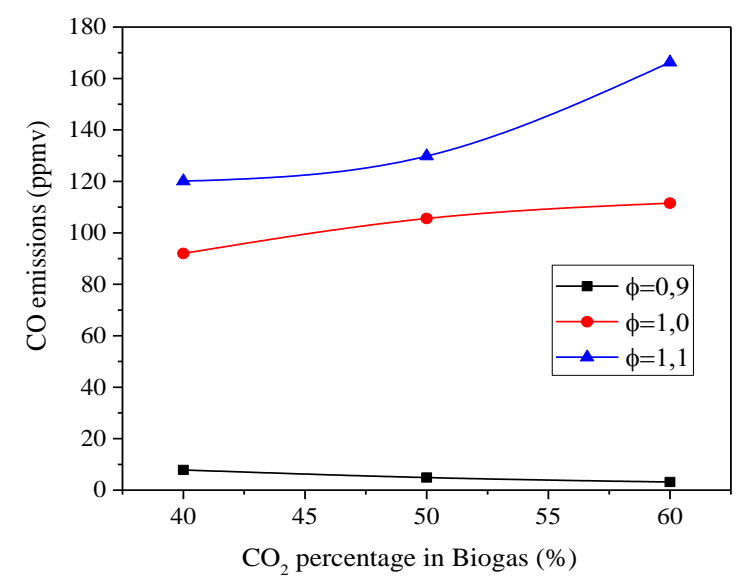

(b)

Figure 3. Variation of (a) $\mathrm{CO}$ emissions versus equivalence ratio $\phi$ and; (b) $\mathrm{CO}$ emissions with $\mathrm{CO}_{2}$ concentration in biogas.

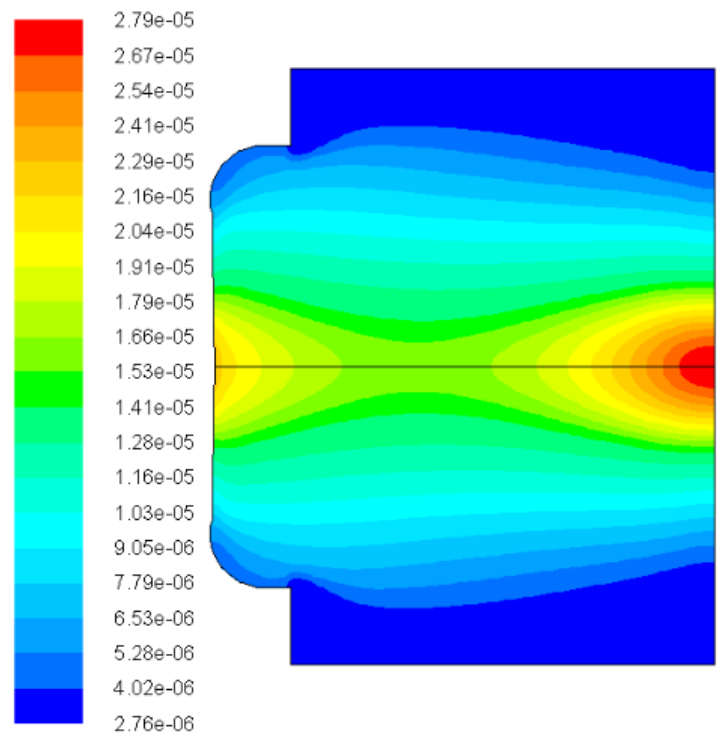

Figure 4. The contour of CO mole fraction $(\mathrm{BG} 60-\phi=0.9)$.

\section{NOx Emissions}

Biogas engines have lower NOx emission because of the lower combustion temperature. The burnt gas temperature was found to be lowered by about $130 \mathrm{~K}$ 
compared to methane and that was sufficient to halve the NO level in the exhaust [19].The variation of NOx emissions from lean to rich mixture conditions for different biogases is presented in Figure 5 (a). It shows that NOx increases with the increase in the concentration of the $\mathrm{CH}_{4}$ for rich mixture conditions and tends to zero in lean conditions for all biogases. In addition, this is due mainly to temperature increase, see Figure 7 (b). This also is in line qualitatively with the experimental results of Porpatham et al. [9]. The variation of NOx emissions with carbon dioxide fraction in the biogas is presented in Figure 5 (b). We observe similar trends of emissions with equivalence ratio to those found by Huang [10]. At the two values of $\phi(0.9$ and 1.0), the NOx emissions fell off significantly as the fraction of carbon dioxide in the biogas mixture increases because of the lower combustion temperature. For $\phi=1.1$, the NOx emissions increase rapidly and this should be due to prompt NOx because of the rich conditions prevailing in the flame [37]. Figure 6 shows that the major part of NOx is formed in the area around the spark plug and it is the result of the high-temperature zone caused by synchronization of ignition by the spark. Predicted NOx have similar trends from other experimental research [38].

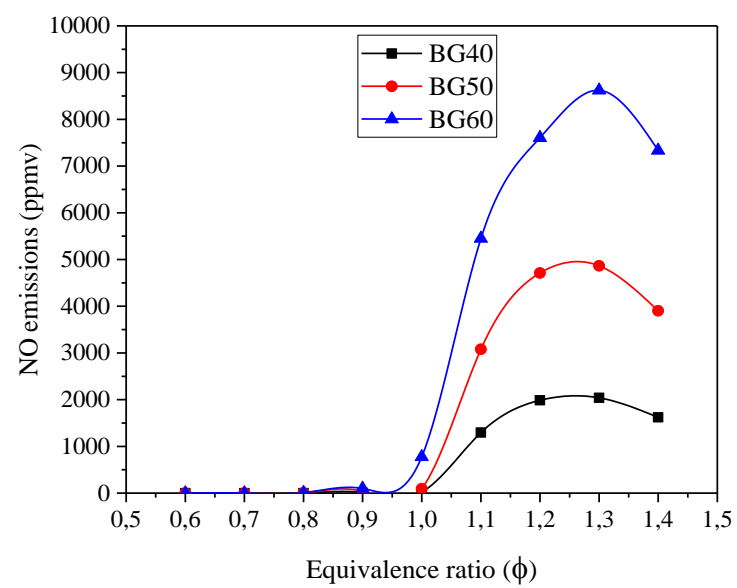

(a)

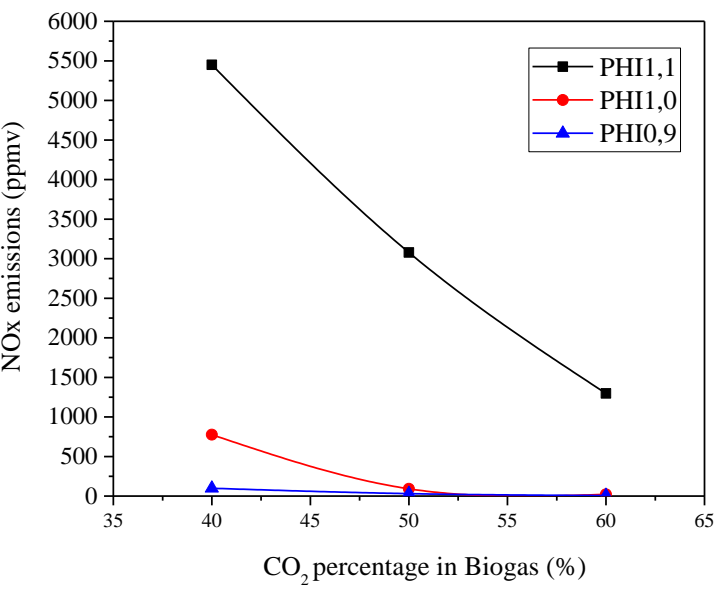

(b)

Figure 5. (a) Variation of NOx emissions versus equivalence ratio $\phi$; (b) Variation of NOx emissions with $\mathrm{CO}_{2}$ concentration.
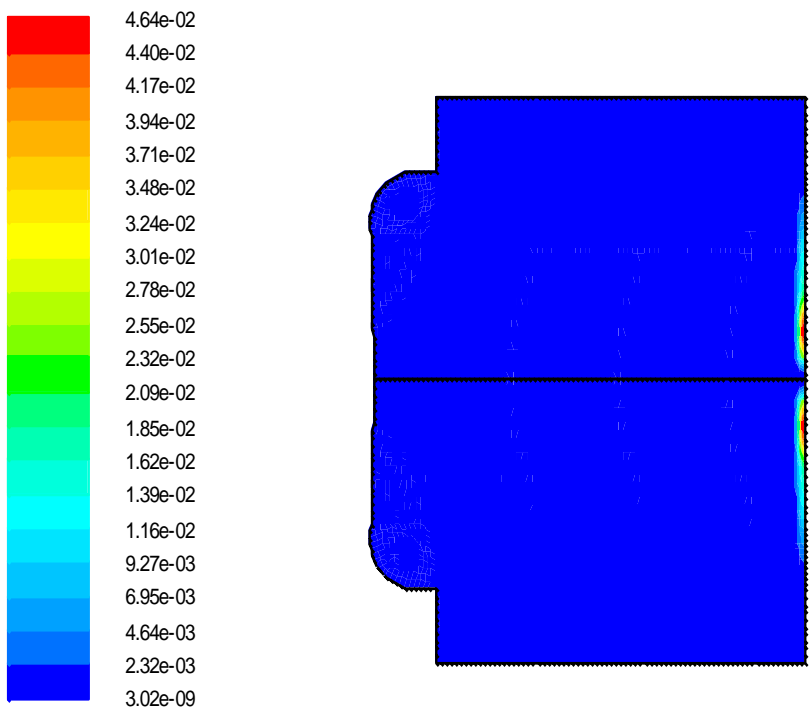

Figure 6. The contour of NOx mole fraction (BG60- $\phi=0.9)$. 


\section{$\mathrm{CO}_{2}$ Dilution Effect}

In Figure 7 (a), we can see that all the oxygen is consumed by $\mathrm{CH}_{4}$ in the rich mixture region for all biogases, and in the lean mixture, the quantity of oxygen raises rapidly due to $\mathrm{O}_{2}$ excess [9]. Figure 7 (b) shows that a reduction in $\mathrm{CO}_{2}$ concentration in biogas, a high concentration of $\mathrm{CH}_{4}$, leads to a fast combustion and thus high temperatures, and the pics tend slightly to the lean mixture region. As carbon dioxide has a high heating value and it even increases with temperature [39], that means in high combustion temperatures lots of heat is absorbed by $\mathrm{CO}_{2}$ and thus reducing the flame temperature significantly [40]. In Figure 7 (c), we see well that the increase in $\mathrm{CO}_{2}$ concentration leads to a decrease in the propagation of the laminar flame speed. The high values are in the rich mixture zones.

\section{Effect of Spark Timing on Emissions}

In spark ignition engines, we need to advance the spark timing to give sufficient time for slower biogas flame to have higher bmep (mean effective pressure) [40], [41]. For the biogas BG60 with a lean mixture $(\phi=0.9)$, it can be deduced from figure 8 that NOx and $\mathrm{CO}$ emission have minimum amounts between the advanced spark timing values between 10 and $20^{\circ}$ (BTDC) and beyond of these values, NOx and CO increase rapidly. While for rich mixture conditions ( $\phi=1.1)$, NOx and CO tend to be stable and have low values [41]. Therefore, it is preferable for the engine to operate under these latter conditions.

\section{Effect on Pressure}

According to Figure 9 (a) and 9 (b), the of pressure peaks significantly increases with the reduction of the concentration of $\mathrm{CO}_{2}$ in lean mixtures. This is due to faster combustion and improved thermal efficiency due to higher $\mathrm{CH}_{4}$ concentration [9]. These peaks reflect the peak temperatures. Figure 9 (b) shows that the peak of cylinder pressure rises with the increase of $\mathrm{CH}_{4}$ concentration in biogas.

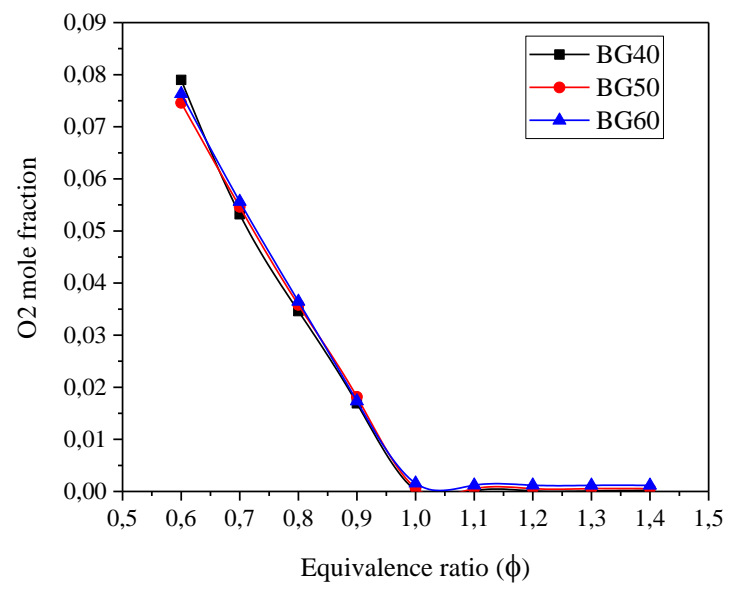

(a)

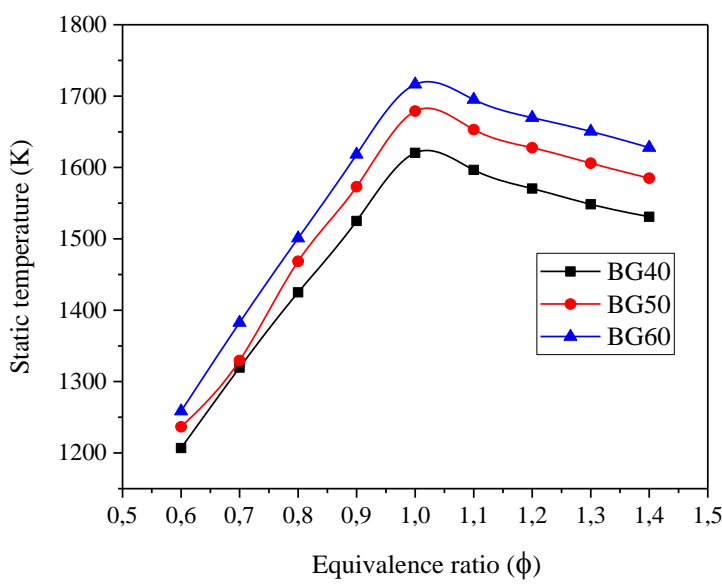

(b) 


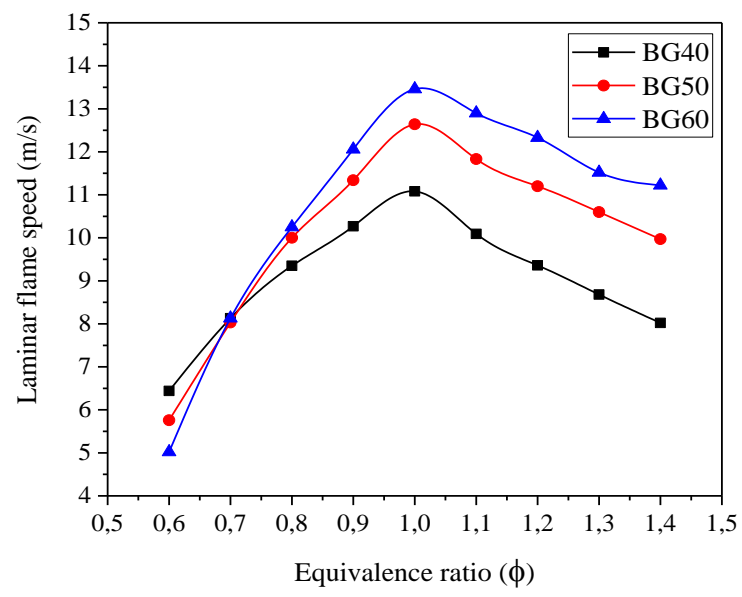

(c)

Figure 7. Variation of (a) $\mathrm{O}_{2}$ mole fractions versus $\phi$; (b) static temperature with $\phi$ and;

(c) laminar flame speed versus $\phi$.

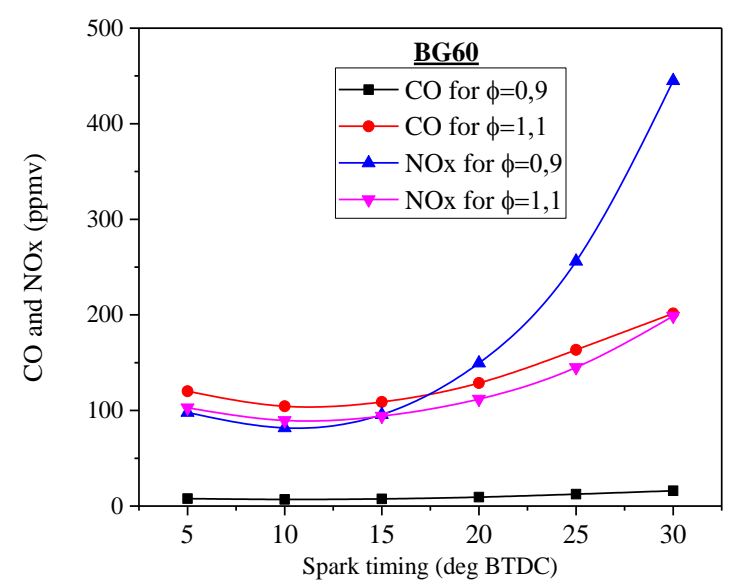

Figure 8. Effect of spark timing on NOx and $\mathrm{CO}$ emissions.

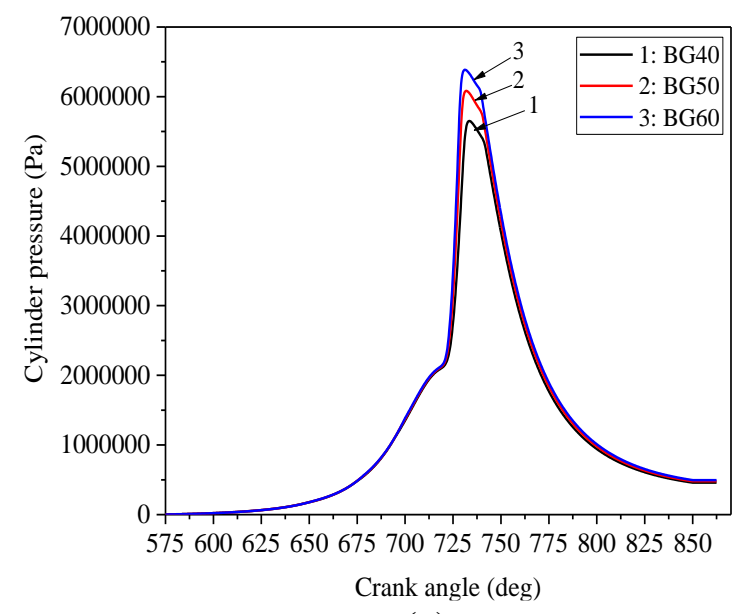

(a)

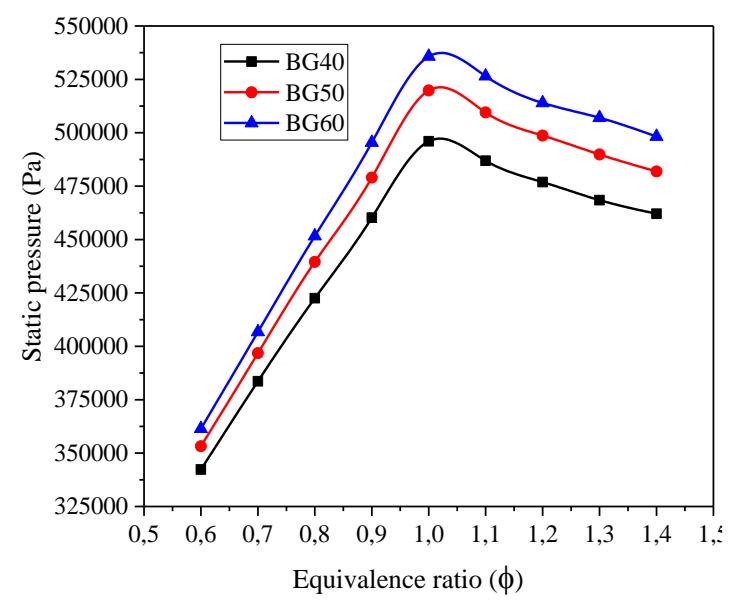

(b)

Figure 9. Variation of (a) cylinder pressure with crank angle and; (b) static pressure versus equivalence ratio $\phi$. 


\section{Unburned Fuel Emissions}

Figure 10 shows that the combustion of our three biogases at different methane composition behaves normally and all the fuel is completely burnt at the crank angle about $740^{\circ}$. The biogas with $60 \% \mathrm{CH}_{4}$ burns rapidly compared to $50 \% \mathrm{CH}_{4}$, which burns more rapidly than the biogas with $40 \% \mathrm{CH}_{4}$ and so forth, which is explained by the higher thermal efficiency due to higher $\mathrm{CH}_{4}$ concentration.

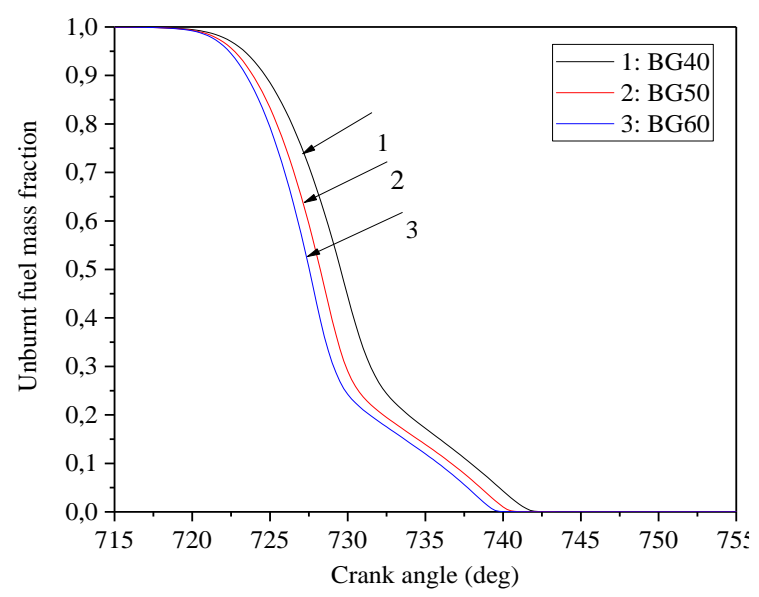

Figure 10. Variation of unburnt fuel versus crank angle.

\section{Biogas Flame Propagation for Different Concentrations of $\mathrm{CO}_{2}$ in The Biogas}

Table 3 represents the contour of progress variable (at the same instant) for different concentrations of $\mathrm{CO}_{2}$ in biogas. We notice that the flame has almost dominated the combustion chamber. The fuel-air mixture in the red colored region is fully burnt and the gradient, which is observed, indicates the partial combustion. As the flame advances, the fuel burns. we notice that the dilution of the fuel by $\mathrm{CO}_{2}$ causes a homogeneous penetration of the flame in the combustion chamber. The lower is dilution, the more the penetration of the flame is fast and occupying the maximum of the volume of the combustion chamber, especially for rich mixtures [25]. In addition, we observe that for the same equivalence ratio $\phi$, the presence of different concentrations of $\mathrm{CO}_{2}$ modifies considerably the propagation of the flame.

\section{VALIDATION}

During last two decades, there have been some studies on the performance and emissions of biogas as a fuel in SI engine; however, their little information available about the combustion process. The results found in this study could be compared to those achieved the other researchers. Concerning the partially premixed model for biogas combustion in SI engines, there is a lack of similar works. We found a study made by Sharath et al. [42], which shows that partially premixed mode is a better viewpoint in engine design.

Regarding emissions, the biogas SI engine studied have lower NOx emission because of the lower combustion temperature. A research has revealed that "burnt gas temperature was found to be lowered by about $130 \mathrm{~K}$ compared to methane and that was sufficient to halve the NO level in the exhaust" [19]. For CO emissions, the simulation showed that they could be low for lean mixtures and not sensitive to the $\mathrm{CO}_{2}$ fraction of 
biogas, but the $\mathrm{CO}$ level increases with a decrease in the amount of $\mathrm{CO}_{2}$. These results are in agreement with those found by [9]. It should be noted that $\mathrm{CO}$ emission for biogas fuel needs more research and studies. $\mathrm{CO}_{2}$ dissociation, combustion temperature, air to fuel ratio and other parameters could have contrary effects on final $\mathrm{CO}$ fraction. We can find more information about the subject of this study in previous papers [43], [44], [45], [46], [47].

Table 3. The contour of progress variable for different concentrations of $\mathrm{CO}_{2}$ in biogas.

$\phi$
$0.8 \mathrm{CO}_{2}$

\section{CONCLUSION}

The simulation results showed that:

a) The concentration of carbon dioxide in the biogas has an important effect on reducing emissions of NOx and $\mathrm{CO}$.

b) The quantity of NOx increases with the increase of the concentration of the $\mathrm{CH}_{4}$ for rich mixture conditions and tends to zero in lean conditions for all biogases.

c) $\mathrm{CO}$ emission is very low and appears only at high concentrations of $\mathrm{CH}_{4}$.

d) It is better for the engine to operate on slightly lean or stoichiometric mixtures conditions; because, in these conditions, the $\mathrm{CO}$ emissions are very low and seems to change little with the variation of the $\mathrm{CO}_{2}$ fraction in the biogas mixture.

e) The highest advantage of decreasing $\mathrm{CO}_{2}$ in the biogas is reached when the engine operates at lean mixtures with an equivalence ratio $\phi$ ranging between $(0.8$ and 1.0).

f) The reduction of $\mathrm{CO}_{2}$ in biogas leads to a higher oxygen and methane concentrations in the mixture and thus leads to a faster combustion and higher output power, especially in slightly rich zones.

g) A biogas with $\left(\mathrm{CH}_{4}: 60 \%, \mathrm{CO}_{2}: 40 \%\right)$, burning at about $(\phi=0.9)$, i.e. slightly lean mixture, and advanced spark timing (between 10 to $20 \mathrm{deg}$. BTDC) seems to be a very acceptable combination.

As a summary, from what has mentioned above, the composition of biogas plays an important role in reducing emissions, especially in terms of CO, NOx, and UHC. This 
means that a considerable effort should be done to upgrade the produced biogas to a higher possible $\mathrm{CH}_{4}$ concentration. It is recommended, however, that further studies should be conducted, to investigate the thermal and chemical effects of $\mathrm{CO}_{2}$, as well as the effect of other biogas components on emissions, amongst others, we site $\mathrm{H}_{2} \mathrm{~S}$ and siloxane.

\section{ACKNOWLEDGEMENT}

The authors would like to acknowledge the help and support of the LPEA research laboratory, Batna1 University.

\section{REFERENCES}

[1] Makareviciene V, Sendzikiene E, Pukalskas S, Rimkus A, Vegneris R. Performance and emission characteristics of biogas used in diesel engine operation. Energy Conversion and Management. 2013;75:224-33.

[2] Deublein D. Biogas from waste and renewable resources: an introduction Second, Revised and Expanded Edition ed: Wiley-VCH Verlag GmbH; 2008.

[3] Porpatham E, Ramesh A, Nagalingam B. Effect of compression ratio on the performance and combustion of a biogas fuelled spark ignition engine. Fuel. 2011;95:247-56.

[4] Chellini R. Jenbacher engines power Bioenergy Park. Diesel \& Gas Turbine Worldwide. Wisconsin 53186-1873, U.S.A2007.

[5] Mameri A, et al. Numerical investigation of counter-flow diffusion flame of biogas hydrogen blends: Effects of biogas composition, hydrogen enrichment and scalar dissipation rate on flame structure and emissions. International Journal of Hydrogen Energy 2016;41:2011-22.

[6] Thipse S. Alternative Fuels Concepts, Technologies and Developments 2nd Edition ed. ed. India: Jaico Publishing House; 2011.

[7] Zhang D. A numerical study of natural gas combustion in a lean burn engine. Fuel. 1998;77:1339-47.

[8] Ferguson C. Internal Combustion Engines. New York: Wiley; 1986.

[9] Porpatham E, Ramesh A, Nagalingam B. Investigation on the effects of concentration of methane in biogas when used as a fuel for a spark ignition engine. Fuel. 2008;87:1651-9.

[10] Huang J. Assessment of simulated biogas as a fuel for the spark ignition engine. Fuel. 1998;77:1793-801.

[11] Jung C, Park J, Song S. Performance and NOx emissions of a biogas-fueled turbocharged internal combustion engine. Energy (Oxford). 2015;86:186-95.

[12] Lee J. A Study on Performance and Emissions of a 4-stroke IC Engine Operating on Landfill Gas with the Addition of $\mathrm{H} 2, \mathrm{CO}$ and Syngas. New York: Columbia University; 2010.

[13] Bedoya ID, Saxena S, Cadavid FJ, Dibble RW. Numerical Analysis of Biogas Composition Effects on Combustion Parameters and Emissions in Biogas Fueled HCCI Engines for Power. J Eng Gas Turbines Power. 2013;135:071503.

[14] Abader R. Study on Biogas-Fueled SI Engines: Effects of Fuel Composition on Emissions and Catalyst Performance. Italy: University of Toronto; 2014.

[15] Arroyo J. Combustion behavior of a spark ignition engine fueled with synthetic gases derived from biogas. Fuel. 2014;117:50-8. 
[16] Pablo G. Spark Ignition Engine Performance And Emissions In A High Compression Engine Using Biogas And Methane Mixtures Without Knock Occurrence. Thermal Science. 2015;19:1919-30.

[17] Narayanan G. Landfill gas - a fuel for IC engine applications. ASME internal combustion engine technical conference. Charleston2007. p. 1623.

[18] Narayanan G, Shrestha SOB. The performance of spark ignition engine fueled with landfill gases. SAE Paper 2006:3428.

[19] Mustafi NN, Raine RR, Bansal PK. The use of biogas in internal combustion engines: a review. ASME internal combustion engine technical conference. Aachen, Germany2006. p. 1306.

[20] Prajapati N, Kumar A. Experimental Study on Utilization of Biogas in IC Engine. International Journal of Engineering Sciences \& Research Technology. 2015;4:827-35.

[21] Bora B, Saha J, Chatterjee UK, Vijay. SV. Effect of compression ratio on performance, combustion and emission characteristics of a dual fuel diesel engine run on raw biogas. Energy Convers. Energy Convers Manag. 2014;87:1000-9.

[22] Kodah Z. Combustion in a Spark-Ignition Engine. Applied Energy. 2000;66:23750 .

[23] Huang J. Spark-Ignition Engine Performance with Simulated Biogas: A Comparison with Gasoline and Natural Gas. Fuel and Energy Abstracts. 1999;40:283-9.

[24] Pulkrabek W. Engineering fundamentals of the internal combustion. New Jersey, USA: Prentice-Hall; 2004.

[25] Carrera J. Numerical study on the combustion process of a biogas spark. ignition engine. Thermal Science. 2013;17:241-54.

[26] ANSYS-FLUENT. Tutorial Guide, Release 14.5. Canonsburg: ANSYS, Inc; 2012.

[27] ANSYS-FLUENT. Theory Guide, Release 14.5. Canonsburg: ANSYS, Inc; 2012.

[28] Zimont V. Gas Premixed Combustion at High Turbulence. Turbulent Flame Closure Model Combustion Model. Experimental Thermal and Fluid Science. $2000 ; 21$.

[29] V. Zimont, W. Polifke. M, Bettelini. W W. An Efficient Computational Model for Premixed Turbulent Combustion at High Reynolds Numbers Based on a Turbulent Flame Speed Closure. J of Gas Turbines Power. 1998;120:526-32.

[30] Lipatnikov V. A Numerical Model of Premixed Turbulent Combustion of Gases. Chem Phys Report. 1995;14:993-1025.

[31] Chavero J. Numerical Analysis of NOx Reduction from Biogas Combustion. Sacramento, USA: California State University; 2012.

[32] Bowman C. Kinetics of pollutant formation and destruction in combustion. ProgEnergCombust. 1975;1:33-45.

[33] Fenimore C. Formation of Nitric Oxide in Premixed Hydrocarbon Flames. The Combustion Institute. 1971:373-80.

[34] Heywood J. Internal Combustion Engine Fundamentals. New York. New York: McGraw-Hill, INC; 1998.

[35] Bergman H. Facts Concerning the Utilization of Gaseous Fuels in Heavy Duty Vehicles. Gaseous Fuels for Transportation Conference. Vancouver, Canada1986. p. 1-35. 
[36] Baskar P, Senthilkumar A. Effects of oxygen enriched combustion on pollution and performance characteristics of a diesel engine. Engineering Science and Technology International Journal 2016;19:438-43.

[37] Kosmadakis GM, Rakopoulos DC, CD. R. Investigation of nitric oxide emission mechanisms in a SI engine fueled with methane/hydrogen blends using a research CFD code. International Journal of Hydrogen Energy. 2015;40:15088-104.

[38] Porpatham E, Ramesh A, Nagalingam B. Effect of compression ratio on the performance and combustion of a biogas fuelled spark ignition engine. Fuel. 2012;95:247-56.

[39] Shrestha SOB, Karim GA. Hydrogen as an additive to methane for spark ignition engine application. International journal of hydrogen energy. 1999;24:577-86.

[40] Karim G. Methane-carbon dioxide mixtures as a fuel. SAE Paper 1992.

[41] Mueller G. Landfill gas application development of the Caterpillar G3600 spark ignited gas engine. Journal of engineering for gas turbine and power. 1995;117:820-5.

[42] Sharath S, Prakash GVN. Simulation and Analysis of in-Cylinder Premixed and Partially Premixed Combustion Modes. International Journal of Engineering Trends and Technology (IJETT). 2015;26:107-14.

[43] Hamada K, Rahman M. An Experimental Study for Performance and Emissions of a Small Four-Stroke SI Engine for Modern Motorcycle. International Journal of Automotive and Mechanical Engineering (IJAME). 2014;10:1852-65.

[44] Yasin MHM, Mamat Rea. Investigation on combustion parameters of palm biodiesel operating with a diesel engine. International Journal of Automotive and Mechanical Engineering (IJAME). 2015;9:2231-8380.

[45] Dubey P, Gupta R. Study of the performance and emission characteristics for a dual fuel powered single cylinder diesel engine. International Journal of Automotive and Mechanical Engineering (IJAME) 2016;13:3373 - 88.

[46] N. R. Abdullah, N.S. Shahruddin, R. Mamat, A. Mohd, I. Mamat, Zulkifli. A. Effects of Air Intake Pressure on the Engine Performance, Fuel Economy and Exhaust Emissions of a Small Gasoline Engine. Journal of Mechanical Engineering and Sciences (JMES). 2014;6:949-58.

[47] Noor M, Wandel A, Yusaf T. The Simulation of Biogas Combustion in a Mild Burner. Journal of Mechanical Engineering and Sciences (JMES) 2014;6:9951013. 